\title{
Sabat Ercasty o el Canto Inabarcable
}

1.-El subtítulo de este ensayo emanó de una lectura fragmentaria de la poesía de Sabat Ercasty. Acercamientos más profundos a esta poética solitaria en nuestra América, me han sorprendido con el acierto definidor de aquellas palabras intuídas más que razonadas.

Como la sinrazón de palabras dichas al azar convertidas más tarde en amenaza profética, así se levanta ahora ante mí esa definición de la poesía de Ercasty. El canto inabarcáble, es, como el "ábrete sésamo" del cuento infantil, un ensalmo que desde el principio nos previene contra la inutilidad de trazar límites y abrir cauces derechos a este arte de aguas tumultuosas y altísimas.

Proyectaba el estudio de Sabat Ercasty desde que leí por primera vez algunos de sus poemas. Le escribí pidiéndole sus obras en marzo de 1937. Me marché al Perú en junio de ese año, sin haber obtenido respuesta a mi carta. Las circunstancias me envolvieron en otros trabajos; el silencio del poeta, despojándome de la única posibilidad existente en Hispanoamérica para estudiar desde lejos a un autor vivo en completa trayectoria, me habían desviado de mi propósito. Pero en diciembre de 1937 me llega desde Montevideo la carta más reveladora que se me ha escrito en lo que llevo vivido. Sabat Ercasty, en cuatro páginas mecanografiadas por él mismo a un espacio, en la forma única de su expresión que es la abundancia, el vértigo metafísico, el golpear doloroso de su pensamiento contra el límite demoníaco de la duda, me resume atro- 
pelladamente, como impelido por vientos ciclónicos, su retrato, su poética y su estética.

De su física apariencia no dice mucho la carta. En el párrafo donde solicita perdón por su retrasada respuesta, con humorismo traído para hacerme sonreír y borrar un ceño imaginario, escribe:

"Déjeme que le bese la mano y le pida' perdón. Qué cuadro! Yo, un hombre de un metro y ochenta centímetros, corpulento, con el cabello cano, puesto de rodillas ante usted". (Sabat me imagina con exactitud, pequeña). Y continúa: "Su bondad me dice: Levántese, señor Sabat... Está perdonado, don Salvaje! Otra vez no lo haga".

Tras de ese parco retrato aparencial - las apariencias sólo interesan a este artista para mirar a través de ellas- traza un tremendo retrato de su intimidad erizada de púas de contradicción. La primera y de hincada más honda, es la de sentirse poeta a veces, cuando desoye las voces negativas de Satán. "Hasta un límite de dolor que sobrepasa todo límite de dolor" le lleva entonces el vuelo de la poesía. Pero el poeta se describe en el torrente de los opuestos:

"A veces camino ciego por el borde de la locura. Tengo la fe de don Quijote y la duda de Hamlet. Espantosas fuerzas combaten en mi pecho. ¿Sabe qué cosa quiere decir Sabat? ¿Recuerda el Fausto? ¿La fiesta de las brujas y los hechiceros? ¿ La misa negra a la media noche? ¿Por qué me llamo Sabat? El aquelarre! $\mathrm{Y}$ toda esta cosa demoníaca que sin duda está en mí con su poder negativo, pelea con el arcángel. Porque también tengo el arcángel y unas alas blancas que pelean con las alas negras. ¿Por qué acercarla tanto a mi verdad? ¿No basta con los versos? ¿No son ellos lo mejor de mi vida? Y yo digo, no! No son lo mejor de mi vida. Hay algo terrible que jamás he podido decir. No. Nadie me conoce. Poetas! Literatos! Genios! Creadores! No. Yo soy la vida. No tengo paciencia para poeta. Ni lima, ni buril. Improviso. Tengo cierto poder de videncia $\mathrm{y}$ cierta inclinación por las artes mágicas".

Sabat Ercasty, pues, transita el camino de poesía denomi- 
nado con la vieja y en nuestro tiempo desacreditada palabra de "inspiración". Fué Platón el primero en distinguir entre la poesía de "buen sentido" y la inspirada, añadiendo que el arte no basta para ser un buen poeta; precisa el soplo de delirio con que las musas sobrecogen al cantor. En el pensar platónico la poesía inspirada eclipsará siempre a la que él llama "de buen sentido". Dos caminos hay, pues, para llegar a lo poético: una tenaz y perfecta atención que ensancha la zona de la conciencia iluminando los resquicios más lejanos, y un dejarse llevar en estado de ensoñación, suprimiendo las facultades conscientes en busca de lo absoluto espiritual. (1)

Paul Valéry representa el método vigilante, activo, en que la conciencia y la atención dominan. En el método opuesto, el de Rimbaud, y en nuestro tiempo el de los surrealistas, los poderes lógicos se suprimen y los sentidos, como en el trance místico, se suspenden. El romanticismo renovó este antiguo concepto de la creación poética, dentro del cual se acoge por voluntad propia, Sabat Ercasty.

2.-Pantheos (2) publicado en 1917 , es el primer libro del poeta y en él están todos los que ha escrito después, como puntos vibrantes que han ido estallando para crecer y definirse. Veintiocho años tenía Sabat Ercasty entonces y ya es La Esfinge quien anuncia en la página inicial, que, si aún pasan cisnes por la cercanía, no son los rubenianos. Hay una oleada cósmica y profunda en este libro donde se afirman cosas tan extrañas en una boca de hombre joven, como éstas: "El beso místico del alma, nos une. El beso carnal nos separa".

El poeta está cantando a una mujer amada:

Yo viajo hacia tu esfinge sobre el hondo misterio que en tus ojos se incuba.

$\mathrm{Y}$ anido en las tinieblas de tus órbitas vagas ebrias de inmensidad como la noche.

Y ya están nombrados los temas de esta poesía, los viejos temas humanos: el misterio, el amor, la vida, la noche. El último en su ampliación metafísica es para los poetas que la han amado, símbolo de la unidad, del paso de lo diferen- 
ciado a lo uno en el seno de la tiniebla; símbolo también de la muerte.

El poeta encuentra en el amor el primer límite donde su interrogáción naufraga:

Pero yo me amortajo de tinieblas

y el hierático rito de tus dioses

oculta inmensamente su secreto

tras una yerta frialdad de bronce.

Definitivamente será desde aquí Sabat Ercasty "el gran río infatigable bajo las vastas sombras". La montaña, el árbol, el cielo estrellado, la tierra, "uva de juegos ufanos", le llevan a pitagóricas conclusiones:

La última esencia de las cosas es una eifra;

Dios piensa con números

Y en la música de sus obras

Llegarás a percibir un día lejano

Los plenos valores de la perfección y de la belleza.

3.-El placer armonioso: Para llegar al placer armonioso el poeta hace un paréntesis en prosa, explicativo de los procesos psíquicos que le convierten en el instrumento de lo desconocido. Pero este milagro sucede en América. Todas sus naves esperan con las proas insaciables de distancias. Piensa el poeta que nuestro esfuerzo irá más allá del esfuerzo de todas las razas. El placer armonioso se exalta en el último poema de Pantheos. Es un canto a la juventud, de la cual él se siente guía. Con júbilo hablan allí las cosas de la tîerra: el mar, el velero estremecido por el viento, las montañas, las llanuras, el cóndor de los Andes, en cuyas pupilas hay siempre un "más allá para la audacia"; la alta noche, en fin, donde la mirada puede reposar en las serenidades largas de los astros. Todo esto es suma del placer armonioso.

4.-La gran sed: Esbozada aparece en Pantheos la gran sed que ha de transformar la vida de Sabat Ercasty, del joven alegre de mirada azul y capa byroniana que describió Juan Parra del Riego al "monje trágico de la poesía, pálido de la palidez que ya no se ve, enflaquecido, desencajado como el 
Dante, alejado de todos los amigos; sin querer quitarle un minuto a la pasión de crear. Más tajante y ardiente su fisonomía, todo en él revelaba la presencia de la vida intensa". (3) $\mathrm{Y}$ es en este momento cuando Sabat acomete la tarea ciclópea de esos "poemas del hombre" en los que se expresa en máxima plenitud:

\footnotetext{
Estrella última de la altísima noche! yo soy el arquero del mundo el ágil cazador de las ciudades y los bosques!
}

Juan Parra del Riego, el poeta peruano que escribió las mejores páginas sobre Ercasty, fué el compañero de las charlas de café y las caminatas por las playas; el cómplice también de aquellas visitas a las estaciones que les hacían sentirse amigos de los maquinistas cuando iban a ver "la llegada gloriosa de una locomotora grande como un altar, Nuestra Señora de la Pasión y de la Fuerza".

5.-Los poemas del hombre-la primera serie es de 1921son el centro de la poética de Sabat Ercasty. Ideó el poeta una especie de Leyenda de los siglos, en donde el hombre, él mismo, es el hilo de continuidad a través de los temas específicamente humanos, lo "subceleste" de que habla Neruda y los temas metafísicos, motivo de su angustia, de "la gran sed".

En el primer volumen se incluyen tres etapas de lo que podríamos llamar viaje del poeta por zonas sucesivas conquistadas: Libro de la voluntad, Libro del corazón, Libro del tiempo. (4)

6.-Los brazos del anhelo, fatigan, en el primer libro, "al viento de la voluntad". El poeta alza su confesión a "la estrella última de la altísima noche". Como para Novalis y Nerval, la noche es para Sabat Ercasty la fusión con el todo, el retorno que nos hace descansar en eterno ritmo, después de la elevación y la caída. Un libro entero escribirá más tarde para cantar "el vuelo de la noche". Ahora su pensamiento converge al fuego lejano de la estrella, resumiendo la angustia - de la voluntad desengañada: 
Mira mi sed, mira mi hambre, mira mi anhelo, Mira mi voluntad alargada entre muda distancia como una inmensa herida.

Una mujer, de mano "dulcemente humana" se interpone aquí para detener la caída ebria y trágica. Su ruego a la amada tiene el dramatismo de aquellos instantes en que el soñador quiere dejar de serlo; quiere vivir la vida como los seres comunes que van ciegos y firmes:

Interrúmpeme la voluntad titánica

Rompe mi proa ardiente con tu grito más ágil.

Agárrame por esta carne débil

hasta anudarme el mundo espeso y fuerte.

Habla a los otros hombres, hermanos en las ataduras con que los obstáculos nos clavan en la tierra. Es ahora la rebeldía voluntariosa:

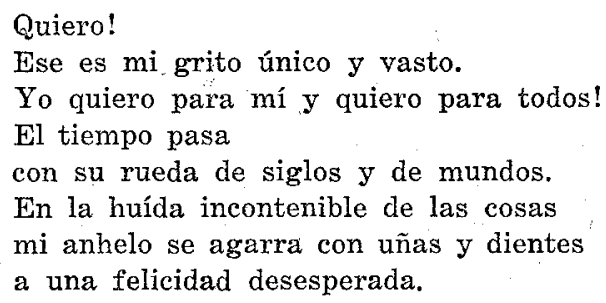

La voluntad es inevitable y fuerte. El poeta sabe que nada ha de detenerle "hasta la gran fatiga en que ahogará su vida". La voluntad, devoradora de la vida, hará de la guerra del poeta dolor nunca sufrido. La sed más alta - lo afirma el poeta- sube a otra sed más alta.

7.-El libro del corazón es canto de carne joven multiplicado en innumerables cantos. Las guerras de la vida son, a la vez, alegres y trágicas. Hay una dación sumisa a los imperativos del corazón rebosante de impulsos vitales:

Como una rama dulce doblada por la fruta entrégate maduro de tu miel a la mano inmensa que impulsa tus corrientes. 
Los nervios son selvas tibias de sensación y luz; de sus músicas y sus ríos se levantan pájaros azules, y el poeta siente el movimiento acelerado de su corazón, labrando su cuerpo como el manantial labra el cauce. $Y$ es jubiloso, lleno de claridad el ondear de sensaciones:

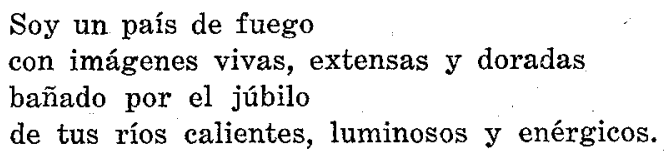

La víscera vil de que habla Carducci, en el poema de Ercasty recibe culto y palabras emocionadas de retorno. El poeta hizo de su vida una gran pregunta y se fué de su corazón en un himno. Ahora vuelve temblando al seguro constante. $\mathrm{Y}$ para siempre quiere acompasar su poesía al latido que se ha vuelto luz y miel:

Levántate en un canto primordial y profundo, como la fuerza que hizo los toros y las águilas levántate en un canto que ofrezca un ala inmensa para darle a los hombres un abrigo de música.

8.-El libro del tiempo es también el libro de la angustia. El tiempo es el gran río donde el poeta se detiene a sentir "los pasos profundos de la eternidad". Hombre del mundo y de las estrellas se describe aquí Sabat Ercasty señalando sus rutas opuestas hacia arriba y hacia abajo, trayendo, de ambas direcciones, la cosecha que ofrece a sus hermanos.

\footnotetext{
Me he puesto a traerte ahora las cosas de más arriba.

He ahí para todos

mis robos profundos a la noche.

Mi raíz trabaja

Mis frutas caen.
}

La noche vuelve a ser en la cobertura de su tiniebla, propicia a las revelaciones. Sus himnos ahora cierran la carne y abren los sueños. Es el trance de angustia producido por un nuevo dolor. Una arruga nueva se le acuesta en la frente. 
Quiere llorar su desventura en cóleras y lágrimas de fuego y sal, lágrimas de varón. La metáfora de un solo término, "me dormiré sobre maderas encendidas" alude a la rebeldía ante el dolor no aguardado. Pero entonces la noche se hará fría y aguda. Sus ojos interiores verán el porqué y el modo de su desconsuelo. $Y$ se levantará con un Eve de fuego en el corazón; despertará resucitado en entusiasmo. Su costado herido llenará de savias nuevas ramas. Los árboles del espíritu se cargarán con las frutas del bien. $\mathrm{Y}$ otra vez el poeta a la orilla del gran río que es el tiempo se verá mordido de fiebre, mas pálido de amor.

9.-Intermisión: Los poemas del hombre se interrumpen ahora con una larga intermisión. El escenario no queda, sin embargo, vacío. Una serie de libros pasan cargados de signos e interrogaciones: Eglogas y poemas marinos (1922), Vidas (1923), El vuelo de la noche (1925), Los adioses en verso, y Los juegos de la frente (1929), reflexiones sobre los temas repetidos en diversos tonos desde la iniciación del poeta. No hay espacio en esta ocasión para analizar todos esos libros; ello es faena de mi inmediato futuro si la vida y las fuerzas me alcanzan. Vidas sobre todo, es inusitado en la producción de Sabat. Su tamaño es breve como una fruta jugosa. En su portada, sobre fondo negro, hay un árbol espeso cargado de manzanas; las manzanas del pecado y de la vida. Hay un prólogo del mismo poeta que nos explica la movilidad hechizante de Vidas: "Ah, con qué sorpresa he renacido cada mañana de mi.vida. Todo ser es sueño y renacimiento". El poeta desdobla una larga tela donde ha pintado - por algo se inclina a las artes mágicas- un friso movible donde unas figuras de mujer graciosas, danzantes, y unos hombres de energía dionisíaca pasan y repasan. Pasa la virgen de la fruta, "virgen de todo hombre, gajo de fruta"; la joven, que danza y corre, pánico frenesí del instinto indeterminado; la joven del fuego "encendida manzana de púrpura", exaltación del anhelo de la sangre; la joven de los campos, con sus quince años llenos de sed que no sacian las uvas, tendida en el llano mientras la luz baila en su cuerpo; la joven del sol que también danza y corre en la ronda de los instintos; la de la luz "toda de fuego y música". Los hom- 
bres después: el de la selva, leñador profundo de salud y trabajo; el de la piedra "hombre claro y ágil" cortador de la montaña con su ardiente martillo; el hombre del fuego, el herrero de pecho alegre "danzando entre la rueda de luz que gira al fuego".

Canto a las dinámicas corrientes de la vida animando juveniles figuras de mujer; canto al trabajo humilde que el poeta ennoblece agrandando la fuerza y la belleza de los menesteres enérgicos y útiles del hombre que trabaja. El poeta suspende aquí su ritmo ancho, parecido al de Whitman, y escribe todo el libro en alejandrinos, con frecuentes asonancias, y ocasionales fugas al verso libre preferido desde Pantheos.

10.-El vuelo de la noche, sugiere exégesis detallada que he de hacer en otra ocasión. El sentido de la noche en poetas cosmogónicos como Sabat Ercasty ha sido comentado por Rolland de Renéville. El vuelo de la noche sería, para el ensayista francés, ejemplo adecuadísimo en que apoyar sus conclusiones.

Ante la inminencia de la noche, Ercasty piensa en el eterno cambio, en lo que ha sido ella, en las filosofías hindostánicas donde cada ciclo cósmico es seguido de una noche cerrada. La sobrecoge la angustia descrita al comenzar el libro:

Cuando en inmensas tardes junto al mar de agua y oro corta un fino horizonte el sol rojo y sediento, y está amarrado el viento y las olas atadas y va a temblar la estrella y va a subir la sombra, y el día retrocede agazapado y turbio, y penetra la noche con su paso insondable y el nacimiento puro y la agonía pálida sobrecogen al hombre que ve el eterno cambio... haciendo un arco oseuro de dolor y fatiga con el cuerpo y el alma, he pensado hasta el fondo que un día seré todo de colores vencidos y bajo el horizonte de la espléndida vida como el sol, lentamente, caeré, pero deshecho, mientras sobre mi carne se hará la noche inmensa. 
Hadas del crepúsculo, de los jardines, de la luna, son bañadas por el velo de la noche. Fantasmas, viajes y caídas surcan las noches del durmiente. Dulzura del amor junto a la amada aunque sean las del amor las más hondas heridas. Metafísica del nacimiento puro en una noche donde su alma pasó con roces inefables y largos, "sobre el dios intangible que sólo el alma roza".

A este libro pertenece el poema "Insomnio". Una imagen náutica es la primera estrofa. El lecho es un barco flotando en el mar del insomnio. El desvelado ve pasar olas y naves en anhelante viajar. Algunas naves inclinan sus velas negras y le hunden los mástiles en el pecho. El insomnio sigue corriendo como un río. Los recuerdos de perdidas dichas le atormentan. Las olas suben. El hombre despierto roza los abismos del sueño. El poeta desea entrar al puerto, descansar al fin en el sueño que no llega. Pero "islas bruscas", preocupaciones, inquietud, destruyen la feliz esperanza. Vértigo y fiebre hinchan los nervios; faros alucinantes atraen la vela de la nave. El poeta desea naufragar, que la proa de su barco se quiebre. El corazón se retuerce de tinieblas. La noche hunde en él su garra constelada. Las estrellas muerden en las nieblas de los ojos y la carne siente más quemantes sus llagas.

Satán es el causante de los insomnios. El construye en su negro astillero con nervios, angustias y locura la barca nocturna del viajero. Subir los bordes de la fatigada vida, llegar a las orillas de la muerte, y no tener ni el reposo del sueño, es destino satánico.

Sigue una enumeración de torturas, gritos, amenazas. Siente en fin el calofrío de lo sobrenatural:

Siento como si todos los astros me tocasen Veo visiones nunca llegadas hasta el mundo Almas desencarnadas parece que rozasen incandescentes, ebrias, mi corazón profundo.

Insomnios desmedidos como su canto e inabarcables como él, donde el hombre que se asomó al misterio padece el castigo de su osadía. 
11.-El dilema de la rosa. ¿Qué solución da este Prometeo a los enigmas que maneja con familiaridad de terribles juguetes? ¿Piensa que todo es vano para el que un día estará muerto, "cansado de su sombra aciaga?" Su dilema es el de la rosa descrita en cuento de aromas persas, al final del libro Loś adioses. Este libro de prosas que se bañan aún del lírico impulso de los poemas, recoge las meditaciones del poeta sobre el temario trascendente ya conocido.

Al comenzar la primavera, ve subir de las entrañas de la tierra el vuelo de las formas. En un rosal, la rosa - aún idea-no quiere vivir. Teme la muerte y el contacto con la realidad. Pero en la noche, una voz celeste entra en el rosal desde una estrella; la rosa se abre lentamente hechizada por el astro. El poeta sabe entonces que la solución del dilema en toda vida - flor, bestia, hombre - es el ejercicio de la virtud esencial que fatalmente la limita y salva.

Concha Meléndez, Universidad de Puerto Rico.

(1).-Ver L'Experience poétique de Rolland de Renéville, París, Gallimard, 1938. 1921.

(2).-Carlos Sabat Ercasty. Pantbeos, Montevideo, O. M. Bertrani,

(3).-Juan Parra del Riego. Montevideo, Boletín de Teso, Núm. $7,1924$.

(4).-Carlos Sabat Ercasty. Los poemas del bombre. Montevideo, 
